Nutrition Science en évolution

La revue de l'Ordre professionnel des diététistes du Québec

\title{
Comment accompagner les familles multiculturelles ?
}

\section{Annie Brodeur-Doucet et Julie Deschamps}

Volume 17, numéro 3, hiver 2020

URI : https://id.erudit.org/iderudit/1068833ar

DOI : https://doi.org/10.7202/1068833ar

Aller au sommaire du numéro

Éditeur(s)

Ordre professionnel des diététistes du Québec

ISSN

2561-620X (numérique)

Découvrir la revue

Citer cet article

Brodeur-Doucet, A. \& Deschamps, J. (2020). Comment accompagner les familles multiculturelles ? Nutrition Science en évolution, 17(3), 26-27.

https://doi.org/10.7202/1068833ar d'utilisation que vous pouvez consulter en ligne.

https://apropos.erudit.org/fr/usagers/politique-dutilisation/ 


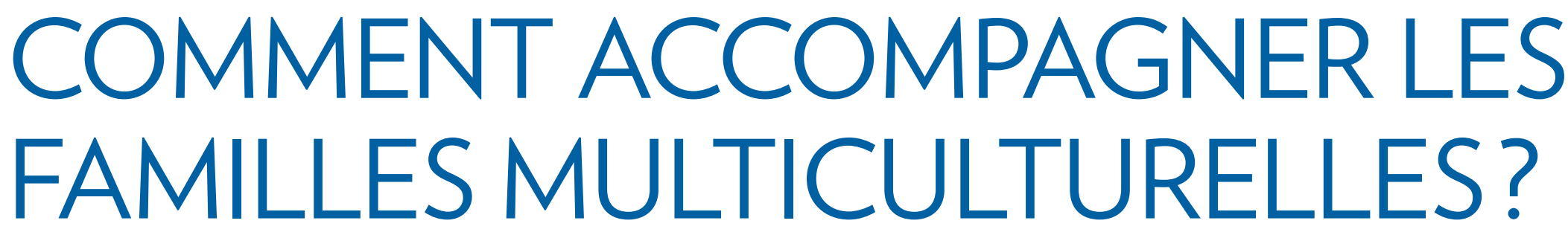

DÉCOUVREZ-EN DES ASPECTS DANS LE GUIDE «DÉCOUVRIR LE MONDE ET SES DIVERSES SAVEURS »

Annie Brodeur-Doucet, Dt.P., directrice de programme et de projets au Dispensaire diététique de Montréal. Julie Deschamps, Dt.P., M. Sc., nutritionniste à la Fondation Olo

\section{L'alimentation au cœur de l'intégration}

À leur arrivée au pays, plusieurs familles immigrantes veulent maintenir leurs habitudes alimentaires et culinaires, car elles font partie de leur bagage culturel. Néanmoins, elles éprouvent souvent de la difficulté à se procurer leurs aliments traditionnels, vu leur disponibilité et leur accessibilité parfois limitées, ainsi que leur coût parfois plus élevé.

À cet effet, des études confirment que ces familles sont souvent à risque de connaître une insécurité alimentaire ou un affaiblissement de leur santé (1-4). C'est pourquoi les nutritionnistes gagnent à connaître les cultures alimentaires de divers pays. Elles peuvent ainsi adapter leurs interventions pour favoriser l'adoption de saines habitudes alimentaires par les familles.

En 1997, la Direction de santé publique (DSP) de Québec a publié le document «Profils alimentaires des principaux groupes ethniques de la région de Québec ». Une mise à jour s'imposait, car le visage de l'immigration a changé depuis les vingt dernières années. Aussi, le Dispensaire diététique de Montréal et la Fondation Olo ont décidé de collaborer pour actualiser ce document.

\section{Objectifs}

Le guide Découvrir le monde et ses diverses saveurs - Profils alimentaires de régions du monde et de quelques aspects culturels liés à la périnatalité a pour objectif premier d'outiller les intervenantes pour mieux accompagner les familles de diverses origines dans leur nouvel environnement culturel et alimentaire. Les intervenantes pourront notamment les aider à relever le défi de cuisiner avec des aliments méconnus, voire inconnus. Par l'entremise de ce guide, les intervenantes :

$>$ établiront plus aisément un lien de confiance avec les familles de diverses origines ethniques;

$>$ sauront mieux accompagner les familles et les femmes enceintes nouvellement arrivées au pays par une meilleure compréhension de leur culture alimentaire et de leurs croyances sur la périnatalité;

$>$ adapteront leurs interventions favorisant la santé, la nutrition et la saine alimentation par l'approfondissement de leurs connaissances et de leurs compétences.

\section{Le guide en quelques mots}

Découvrir le monde et ses diverses saveurs se veut un outil de référence incontournable sur les habitudes alimentaires et culinaires des communautés culturelles issues de l'immigration. En présentant les profils alimentaires de 11 régions du monde regroupant 44 pays, ce guide dresse le portrait actuel de la diversité culturelle du Québec.

\footnotetext{
Pour chaque pays, on retrouve:

$>$ La représentation d'un repas type;
}

$>$ Les comportements alimentaires à valoriser et à modifier pour favoriser de saines habitudes alimentaires ;

$>$ Les patrons alimentaires habituels regroupant l'ensemble des aliments consommés au cours d'une journée type;

$>$ Un lexique des mets communément consommés au sein de la population;

$>$ Les croyances et coutumes relatives à l'alimentation de la femme enceinte et la période périnatale.

\section{Développement du guide}

Le projet s'est déroulé de juillet 2016 à septembre 2017. En voici les grandes étapes :

1. Définition des besoins de mise à jour en se basant sur le document intitulé « Profils alimentaires des principaux groupes ethniques de la région de Québec».

2. Participation de plusieurs intervenantes en nutrition sociale du Dispensaire diététique de Montréal ainsi que de la communauté de pratique de la Fondation Olo à la rédaction du document (près de 50 collaboratrices, majoritairement des nutritionnistes).

3. Consultation de ressources matérielles (articles, livres de recettes, présentations et documents de travail concernant diverses cultures).

4. Validation des profils auprès des familles originaires de différentes cultures.

C'est à travers de nombreuses rencontres avec ces familles (clientes du Dispensaire diététique de Montréal et familles Olo) que les portraits alimentaires ont été dressés et que quelques aspects culturels liés à la périnatalité 
ont été précisés. Afin de procéder à la validation des profils, un total de 108 participantes ont été rencontrées, 5 groupes de discussion ont été formés et 95 rencontres individuelles ont eu lieu.

L'un des défis a été de veiller à ce que les profils alimentaires soient représentatifs des immigrants de chacun des pays choisis. C'est pourquoi les portraits dressés sont assez généraux pour qu'ils s’appliquent à la très grande majorité des familles de ces pays, tout en étant suffisamment précis pour que ces dernières puissent s'y reconnaître. Le document a été réalisé avec des familles provenant des régions de Montréal ou de Québec. De ce fait, il est fort probable que l'accès aux aliments multiethniques ne soit pas le même dans l'ensemble de la province.

\section{Utilisation du guide dans la pratique}

«Comprendre la réalité des autres » et «vivre ensemble» sont des concepts incontournables pour intégrer les familles de toutes les cultures. Le guide intègre ces concepts dans la pratique des intervenantes de l'ensemble du Québec et répond aux multiples questions qu'elles se posent. Annie Desmarais, diététiste/nutritionniste au CIUSSS de l'Estrie-CHUS fait part de ce commentaire: «Je me sers des mets communs et du lexique pour améliorer ma connaissance des aliments et des termes utilisés selon les pays. ".

Plus concrètement, l'outil a permis aux intervenantes de se familiariser avec la culture des femmes qu'elles ont suivies et d'adapter leurs interventions auprès des familles immigrantes en ayant une meilleure compréhension de leur bagage culturel. Une meilleure compréhension et l'utilisation d'un vocabulaire commun se sont révélées une stratégie gagnante pour créer un lien de confiance. À ce sujet, Marie-Michelle Côté, diététiste/nutritionniste au CIUSSS du Saguenay-Lac-Saint-
Jean, précise que l'outil lui permet de mieux préparer ses rencontres et qu'il diminue les risques d'erreur. Elle rapporte cette anecdote: «Une cliente m'a parlé de sa consommation de "jus" que j'aurais eu tendance à vouloir diminuer. En consultant le guide, j’ai su que pour elle, un jus était plus comme un smoothie chez nous, donc riche et varié. J'ai donc demandé plus de détails sur la composition de ce jus et cela a vraiment eu un bel impact sur mon évaluation nutritionnelle.» Pour sa part, Ouardia Zeggane, diététiste/nutritionniste au Dispensaire diététique de Montréal mentionne: « J'utilise le guide des profils alimentaires pour créer, entre autres, un lien de confiance avec mes clientes. Voir le sourire et la surprise sur leur visage quand je leur nomme un plat ou un aliment typique de leur pays me fait toujours chaud au cour. De plus, le guide me permet d'avoir une meilleure compréhension des habitudes alimentaires et des coutumes et croyances qui peuvent influencer celles-ci, tant durant la grossesse qu'en période postnatale (p. ex. l'allaitement). Je peux ainsi adapter mon approche et mes recommandations pour favoriser une meilleure adhésion ».

\section{Retombées}

D'abord conçu pour les intervenantes en périnatalité, le contenu unique de ce guide est pertinent pour l'ensemble des acteurs œuvrant en contexte multiculturel. Selon le financement disponible, il est possible de créer des outils qui favorisent la saine alimentation des immigrants (p. ex. fiches informatives) et un module de formation à l'intention des intervenants pour adapter leur pratique à des clientèles de diverses cultures. Dans la même lignée, la volonté de mieux comprendre l'alimentation des populations des Premières Nations a été exprimée par les intervenantes, ce qui pourrait donner lieu au développement d'un guide décrivant l'alimentation de ces dernières.

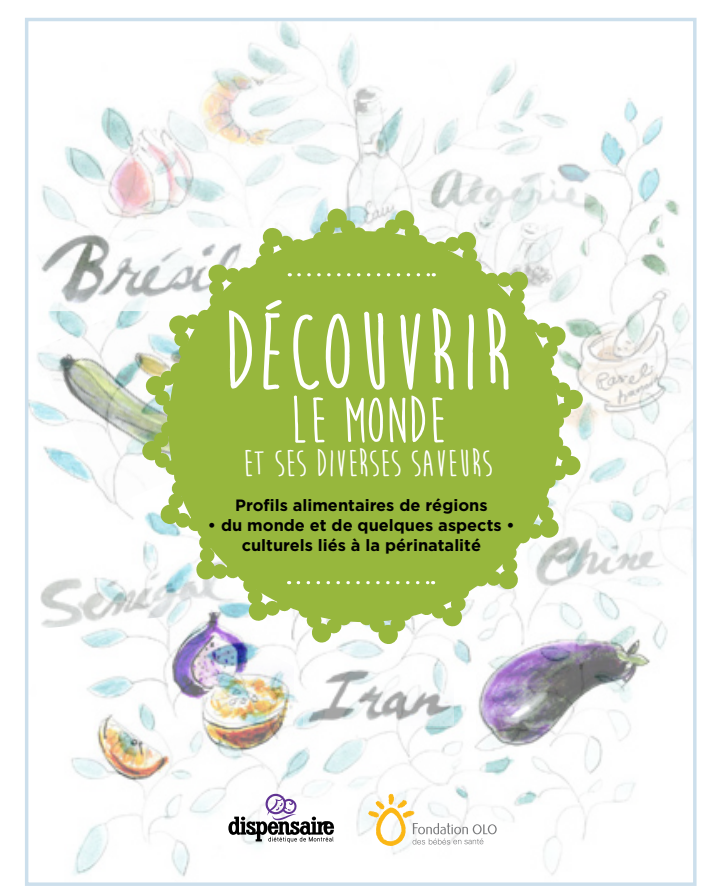

Téléchargez le guide sans plus tarder pour en connaître davantage sur l'alimentation de diverses cultures sur le site web de la Fondation Olo ou celui du Dispensaire diététique de Montréal. Il est aussi possible de le commander auprès de la Fondation Olo. À ce jour, plus de 500 copies ont été distribuées au Québec et la page web du guide a été vue plus de 5000 fois depuis le lancement.

Finalement, la réalisation de ce projet a valu à ses auteures le Prix Innovation, remis par l'Ordre professionnel des diététistes du Québec à l'automne 2017.

\section{Références}

1. Perreault G. et MJ. Riel. Cibler pour mieux intervenir en matière de sécurité alimentaire. Bulletin Vision Santé publique. 2014; numéro 14.

2. Moffat T., C. Mohammed and K. B. Newbold. Cultural Dimensions of Food Insecurity Among Immigrants and Refugees. Human Organization. 2017; 76(1): 15-27.

3. Kohnen CA. Household Food Insecurity Among Recent Immigrants to Canada: A quantitative analysis. In partial fulfillment of the requirements for the degree of Master of Arts (MA), Ryerson University. 2014.

4. Blanchet R., CP. Nana, D. Sanou, M. Batal and I. Giroux. Dietary acculturation among black immigrant families living in Ottawa-a qualitative study. Ecology of food and nutrition. 2018; 57(3): 223-245. 